\title{
CHEMISTRY OF PENICILLIN
}

$\mathrm{T}$ HIS brief summary of results obtained by British and American chemists, issued under the joint auspices of the Committee on Medical Research (Office of Scientific Research and Development, Washington) and the Medical Research Council (London), is a preliminary notice of the principal findings secured up to the end of 1944 in a collaborative effort of a large number of investigators, unnamed at present. It implies some corrections of published data ; authors of early publications are among those who have cleared up these points. For the sake of clearness, the account is not given in chronological order. of development. The primary object of this communication is to disclose significant facts which have been confirmed by unequivocal synthesis and to record a fow essential points which are still matter for conjecture. Full details will be disclosed at a later stage, together with an account of experiments not referred to in this report.

Several antibiotics of the penicillin class are known and all have the empirical formula $\mathrm{C}_{9} \mathrm{H}_{11} \mathrm{O}_{4} \mathrm{SN}_{2} R$. In penicillin-I (known in America as $F^{\prime}$-penicillin), $R$ is $\Delta^{2}$-pentenyl, $-\mathrm{CH}_{2} \cdot \mathrm{CH}=\mathrm{CH} \cdot \mathrm{CH}_{2} \cdot \mathrm{CH}_{3} ; \quad$ in dihydropenicillin-I, $R$ is $n$-amyl; in penicillin-II (known in America as $G$-penicillin), $R$ is benzyl ; in penicillin-III (also known as $X$-penicillin), $R$ is $p$-hydroxybenzyl. In $K$-penicillin (a recent addition to the series) $R$ is $n$-heptyl. The best elementary analyses are of pure crystalline sodium salts. Determinations of the molecular weights of the sodium salt and of the methyl ester of penicillin-II indicate that the empirical formulæ truly represent the molecular weights.

The penicillins are strong monobasic acids of $p \mathrm{~K}$ about $2 \cdot 8$; electrometric titration does not disclose the presence of a basic group. Slow titration with perchloric acid in acetic acid solution indicates such a group, but the penicillin is biologically inactivated by this troatment; rapid titration gives a negative result.

The ultra-violet and infra-red absorptions, crystal structure (by X-ray methods including full electron distribution of the rubidium salt of penicillin-II), and polarimetric and polarographic behaviour of the penicillins and their derivatives have been studied.

Sodium penicillin-II contains one hydrogen atom replaceable by deuterium on equilibration with heavy water.

On treatment with hot dilute mineral acids the penicillins afford one molecule of carbon dioxide, an amino-acid termed penicillamine and other products. Penicillamine, obtainable by several other degradation processes, has been identified by analytic and synthetic methods as $d$ - $\beta, \beta$-dimethylcysteine. Penicillamine with the same steric configuration is derived from penicillins-I and -II ; it belongs to the $d$ - or 'unnatural' series of $\alpha$-amino-acids.

Synthetic penicillamine has been resolved and numerous derivatives of the optically active enantiomorphs and the racemic form have been prepared. These include penicillamine disulphide (tetramethylcystine) and penicillaminic acid (dimethylcysteic acid) as well as a long series of thiazolidines, and $\mathrm{S}$ - and $\mathrm{N}$-substituted derivatives.

After removal of penicillamine from the acid hydrolysates, careful treatment of penicillin-I allowed of the isolation of an aldehyde, $\mathrm{C}_{8} \mathrm{H}_{13} \mathrm{O}_{2} \mathrm{~N}$, in the form of its 2:4-dinitrophenylhydrazone and its condensation product with dimedone. Similarly, dihydropenicillin-I gave rise to derivatives of an aldehyde, $\mathrm{C}_{8} \mathrm{H}_{15} \mathrm{O}_{2} \mathrm{~N}$. Penicillin-II afforded phenaceturic acid, phenylacetamide and an aldehyde, $\mathrm{C}_{10} \mathrm{H}_{11} \mathrm{O}_{2} \mathrm{~N}$. Phenylacetic acid had previously been recognized as a hydrolytic product of penicillin-II.

These penillo-aldehydes have been identified by analysis and synthesis as follows : penillo-aldehyde-I, $\Delta^{2}$-hexenoylaminoacetaldehyde; dihydropenillo-aldehyde-I, $n$-hexoylaminoacetaldehyde ; penillo-aldehyde-II, phenylacetylaminoacetaldehyde.

It was inherently probable that the carbon dioxide liberated when penicillin is hydrolysed in hot acid solution was derived from an unstable carboxyl group and, taking into consideration the nature of penicillamine and the penillo-aldehydes, a probable precursor was penillo-aldehyde-carboxylic acid, CHO.CH $\left(\mathrm{CO}_{2} \mathrm{H}\right) . \mathrm{NH}$.COR, now termed a penaldic acid. This was conclusively demonstrated to be correct.

Penicillin-II and benzylamine afford a crystalline compound, $\mathrm{C}_{30} \mathrm{H}_{36} \mathrm{O}_{4} \mathrm{~N}_{4} \mathrm{~S} . \mathrm{H}_{2} \mathrm{O}$, which has the composition of a hydrated addition compound of one molecule of penicillin-II and two molecules of benzylamine and is the mono-benzylamine salt of the monobenzylamide of a dicarboxylic acid. Degradaticn of this substance by means of mercuric chloride afforded penicillamine and penaldic-II acid benzylamide which was catalytically reduced to hexahydrophenylacetylserine hexahydrobenzylamide, $\mathrm{C}_{6} \mathrm{H}_{11} \cdot \mathrm{CH}_{2}$.CO.NH. $\mathrm{CH}\left(\mathrm{CH}_{2} \mathrm{OH}\right) \cdot$ CO.NH.C $\mathrm{H}_{13}$, identified with a synthetic specimen.

The penicillins are readily inactivated by methanol and the products are methyl esters. Methanolinactivated penicillin-II was degraded to methylpenaldate-II, CHO.CH( $\left.\mathrm{CO}_{2} \mathrm{Me}\right) \cdot \mathrm{NH} . \mathrm{CO} . \mathrm{CH}_{2} \mathrm{Ph}$, the constitution of which was proved by its catalytic reduction to $\mathrm{N}$-hexahydrophenylacetylalanine. The latter was identical with a specimen prepared by similar reduction of phenylacetylalanine. Penicillins-I and -II are converted by the action of diazomethane into mono-methyl esters and these are degraded by mercuric chloride in aqueous solution with formation of the methyl ester of penicillamine.

These observations serve to show (1) that the acidic group in penicillin is identical with the carboxyl group in penicillamine, (2) that by the addition of the elements of water to penicillin a second carboxyl group is produced, (3) that it is this new carboxyl which breaks down to carbon dioxide by the action of hot dilute mineral acids.

The dicarboxylic acid obtained by hydrolysis of penicillin at the site of the potential carboxyl is termed penicilloic acid. This acid is produced in the form of salts by treatment of penicillin with alkalis, and is presumably the product of the action of the enzyme penicillinase on penieillin.

Derivatives of penicilloic acid have been synthesized and the outcome of much work that cannot here be deseribed in detail is that penicilloic acids are undoubtedly thiazolidines of the formula:

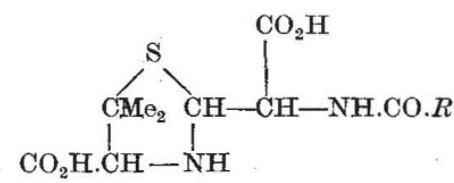


where $R$ is one of the groups already particularized. Thus 'methanol inactivated' sodium penicillin-II is one of the stereoisomeric forms of the structure :<smiles>CCCCCCC(NC(=O)[C@H](NC1CSC1[N+](=O)[O-])C(C)=O)C(C)=O</smiles>

When any of the penicillins is held in dilute mineral acid solution at about $30^{\circ}$, a change occurs which may be followed polarimetrically. Crystalline isomerides of the penicillins termed penillic acids may then be readily isolated. These substances are shown by electromstric titrations to be dibasic acids containing a basic group : thiol groups are absent.

Treatment of the penillic acids with cold aqueous mercuric chloride involves loss of a molecule of carbon dioxide and formation of substances termed penillamines. These compounds are monobasic, mono-acidic and contain a thiol group.

Analysis and synthesis have shown that the annexed expressions represent the respective structures<smiles>CC(=O)C1SC2C(C(=O)O)N=NC12</smiles>

Ponillic acids

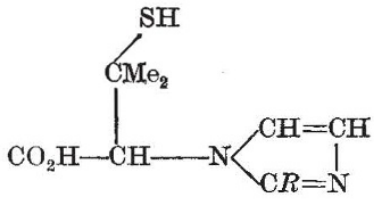

Penillamines
Penillic-I and II acids are convertible by baryta into the isomeric isopenillic acids.<smiles>[R]C1=NC(=O)C(C=O)N1C(=O)O</smiles>

Isopenillic acids

Hydrolysis of the penillic acids by hot dilute acids affords penicillamine, the penillo-aldehydes and carbon dioxide; but the penillamines are resistant to hydrolysis.

Methyl penicillin-II is changed by mercuric chloride in neutral media into the isomeric methyl penicillenate-II which, on hydrolysis by means of aqueous sodium hydroxide, affords the sodium salt of 4-hydroxymethylene-2-benzyloxazolone. The addition of the elements of thiocyanic acid to methyl penicillin and the transformations of the primary product have been investigated in detail with important results.

Finally, the action of Raney nickel catalyst on sodium penicillin-II in aqueous solution affords desthio-penicillin-II, $\mathrm{C}_{16} \mathrm{H}_{20} \mathrm{O}_{4} \mathrm{~N}_{2}$, together with phenacetyl-l-alanyl- $d$-valine, $\mathrm{C}_{16} \mathrm{H}_{22} \mathrm{O}_{4} \mathrm{~N}_{2}$.

Naturally the workers in this field have formed views as to the full constitution of the penicillins. At present it can be stated that the formulæ which are now receiving the most active attention contain respectively a $\beta$-lactam structure (I) and an incipient azlactone grouping (II) :<smiles>CC(=O)NC1C(=O)N2C1SC2[N+](=O)[O-]</smiles>

(I)<smiles>[R4]OC(=O)C1NC(=O)C1N=[W]</smiles>

(II)

The following groups have participated in the joint programme for the chemical study of penicillin.

IN BRITAIN :

Boots Pure Drug Company, Ltd.*

British Drug Houses, Ltd.*

Cambridge University, Department of Chemistry. Cambridge University, Department of Colloid Science. Glaxo Laboratories, Ltd.*

Imperial Chemical Industries, Ltd. (Alkali Division). Imperial Chemical Pharmaceuticals, Ltd.

Imperial College of Science, London, Department of Organic Chemistry.

The London Hospital Medical Unit.

Manchester University, Department of Chemistry.

May and Baker, Ltd.*

National Institute for Medical Research, Hampstead, London.

Oxford University, Department of Crystallography. Oxford University, Dyson Perrins Laboratory.

Oxford University, Sir William Dunn School of Pathology.

Oxford University, Department of Physical Chemistry.

Wellcome Foundation, Ltd.*

IN THE UNITEd States:

Abbott Laboratories.

U.S. Department of Agriculture, Northern Regional Research Labcratory.

Cornell University Medical College, Department of Biochemistry and Russell Sage Institute.

Cutter Laboratories.

Federal Security Agency, Food and Drug Administration.

Harvard University, Department of Chemistry.

Heyden Chemical Corporation.

University of Illinois, Department of Chemistry.

Eli Lilly and Company.

Merck and Company, Inc.

University of Michigan, Department of Chemistry.

University of Michigan, Department of Physics.

National Bureau of Standards.

Naval Medical Research Institute.

Parke, Davis and Company.

Chas. Pfizer and Company, Inc.

The Rockefeller Institute for Medical Research.

Shell Development Company.

Squibb Institute for Medical Research.

The Upjohn Company.

Winthrop Chemical Company, Inc.

* Members of the Therapeutic Research Corporation of Great Britain, Itd. 